\title{
INFLUENZA IMMUNIZATION: IMPROVING COMPliance of HealthCARE Workers
}

\author{
Stephan Harbarth, MD; Claire-Anne Siegrist, MD; Jean-Claude Schira, MD; \\ Werner Wunderli, MD; Didier Pittet, MD, MS
}

\begin{abstract}
OBJECTIVE: In spite of yearly recalls, influenza immunization rates of healthcare workers (HCWs) remained low (10\%) at the University Hospitals of Geneva. This study was conducted to identify HCWs' reasons for rejection of immunization, to design specific intervention methods based on these reasons, and to evaluate the impact of such interventions.

METHODS: Three departments with high-risk patients (geriatrics, obstetrics, and pediatrics) were selected as main targets. Questionnaires were distributed in these units. Based on HCWs' perceptions, different intervention methods were designed and used either in these departments only (educational conferences, on-site availability of a vaccination nurse) or in the whole institution (posters, personal letters). Immunization rates were collected throughout the institution.

RESULTS: 797 completed questionnaires from 1,092 HCWs (73\%) were returned. Major reasons for immu-

nization rejection were confidence that their bodies' selfdefense mechanisms would ward off infection (32\%), perception of low exposure risk (23\%), and doubts concerning vaccine efficacy (19\%). The use of intervention methods designed to address these factors increased influenza immunization rates in the three targeted departments from $13 \%$ (95\% confidence interval [CI ${ }_{95}$ ], 11.4-15.6) in 1995 and 1996 to 37\% (CI95, 34.5-40.3) in the following season $(P<.001)$. In all other departments, immunization rates rose from 9\% ( $\left.\mathrm{CI}_{95}, 8.5-10.3\right)$ to $23 \%\left(\mathrm{CI}_{95}, 21.6-24.1 ; P<.001\right)$. Nurses were, and remained, more reluctant to be immunized compared to other HCWs.

CONCLUSIONS: Influenza immunization rates can be increased significantly by specific interventions based on local concerns of HCWs, among which educational conferences and the on-site availability of a vaccination nurse appeared important (Infect Control Hosp Epidemiol 1998;19:337-342).
\end{abstract}

Influenza immunization of hospital staff is recommended to decrease the risk of influenza transmission to hospitalized high-risk patients. ${ }^{1-3}$ Despite present recommendations, however, only a minority of healthcare workers (HCWs) accept yearly influenza immunization. ${ }^{4-6}$

At the University Hospitals of Geneva (HUG), Switzerland, a 1,500-bed healthcare center providing primary and tertiary care for Geneva and the sur- rounding areas, rates of vaccination for HCWs also remained woefully low (1995-1996, 10\%) in spite of yearly recalls. This study was conducted in three high-risk departments (geriatrics, obstetrics, and pediatrics) at HUG to identify $\mathrm{HCWs}$ ' reasons for rejection of immunization, to design specific intervention methods in view of these reasons, and to evaluate the impact of such interventions in the selected areas and in the remaining departments.

From the Infection Control Program (Drs. Harbarth and Pittet); the Center for Neonatal Vaccination (Dr. Siegrist); the Department of Employee Health (Dr. Schira); the Laboratory of Virology (Dr. Wunderli), University Hospitals of Geneva, Geneva, Switzerland.

The authors are indebted to Philippe Sudre, Nadia Colaizzi, Sinclair Wynchank, the team of the Employee Health and Infection Control Program, and all the other participating and promoting staff members.

This paper was presented in part at the Eighth European Congress of Clinical Microbiology and Infectious Diseases, Lausanne, Switzerland, May 25-28, 1997. Abstract P1413.

Address reprint requests to Stephan Harbarth, MD, Infection Control Program, Department of Internal Medicine, Hôpital Cantonal Universitaire, 1211 Geneva 14, Switzerland.

97-OA-065. Harbarth S, Siegrist C-A, Schira J-C, Wunderli W, Pittet D. Influenza immunization: improving compliance of healthcare workers. Infect Control Hosp Epidemiol 1998;19:337-342. 


\section{METHODS}

\section{Objectives and Design}

The main objective of this study was to survey the attitudes of HCWs regarding influenza vaccine and their reasons for accepting or refusing it in three targeted departments with high-risk patients for nosocomial influenza (geriatrics, obstetrics, and pediatrics). Based on the results of the survey, efforts were made to improve HCWs' compliance with influenza immunization by designing specific intervention methods either restricted to these areas or applied to the entire institution.

In June 1996, a questionnaire consisting of 24 multiple-choice questions was distributed to 1,092 employees in the three selected departments. The questionnaire asked for specific information on knowledge, attitudes, and behavior regarding influenza and influenza vaccine. Additional information was requested regarding previous experience with influenza vaccination or homeopathic alternatives to immunization, intention towards accepting influenza vaccination in the upcoming season, and proposals to improve likelihood of influenza vaccination.

Based on HCWs' perceptions, different intervention methods were designed to increase compliance. In the three high-risk departments, educational conferences were organized addressing specifically the questions identified as main reasons for reluctance to influenza immunization. Furthermore, to decrease logistical obstacles to immunization, a specially trained employee health nurse took a vaccine tray to various wards, clinics, and conferences attended by HCWs.

The following methods were applied in the entire institution: a newsletter was printed, reminders were inserted in the daily electronic-mail message system, and personal letters were sent with the paycheck to encourage employees to be immunized. Color posters were produced to highlight the key messages, as well as the times, dates, and sites of the immunization clinics. Starting in the first week of October 1996, HCWs were offered free influenza immunization, as during previous years, in the employee health clinic. Immunization rates for $\mathrm{HCWs}$ were collected throughout the whole institution.

\section{Statistical Analysis}

Differences in influenza vaccination rates were computed using the chi-squared test for binomial proportions. Means were compared by unpaired $t$ tests, and 95\% confidence intervals $\left(\mathrm{CI}_{95}\right)$ were calculated with the method described by Fleiss. ${ }^{7}$ All tests for significance were two-tailed; $P$ values $<.05$ were considered significant.

\section{RESULTS}

\section{Survey}

Responses were obtained from 797 (73\%) of 1,092 employees, including 378 nursing personnel (47\%), 36 physicians (5\%), and 57 midwives (7\%). A total of 1,573 responses were analyzed (up to six reasons could be listed by each employee). Reasons for rejection of influenza immunization are listed in decreasing frequency in Table 1. Overall, the three most frequently cited reasons for nonacceptance of immunization by $\mathrm{HCW}$ s were confidence that their bodies' self-defense mechanisms would ward off infection $(258,32 \%)$, supposed low likelihood to get influenza disease $(180,23 \%)$, and doubts about vaccine efficacy $(154,19 \%)$. Notably, $14 \%$ of employees believed in homeopathic medicine to protect themselves against influenza. When asked what information or measure could stimulate accepting influenza vaccination in the upcoming season, employees stated that vaccine efficacy should be better documented $(306,38 \%)$; the fact that only minor side effects of the vaccine are expected should be better documented $(146,18 \%)$; and that more convenient immunization services should be offered $(122,15 \%)$.

Differences were noted in the attitudes of nursing personnel $(\mathrm{n}=378)$ compared to other surveyed HCWs ( $n=419)$. Nursing personnel were more reluctant to receive immunization compared to other HCWs; they rejected immunization with more answers justifying noncompliance compared to other categories of HCWs (mean number, 2.2 vs 1.7; $P=.08)$. Furthermore, nursing personnel more often ignored the likelihood of contracting influenza $(P<.001)$ and were less convinced of vaccine efficacy $(P=.02)$. In contrast, groups of HCWs other than nursing personnel more frequently offered inconvenient vaccination hours as a reason for noncompliance with vaccination $(P=.01$, Table 1$)$.

Knowledge about possible nosocomial transmission of influenza and consequences for patients' health was suboptimal; however, only 108 (13.5\%) of 797 employees asked for more information on influenza-associated hospital problems.

\section{Immunization Campaign}

After assessment of the factors affecting acceptance or refusal of influenza vaccine by HCWs, several intervention methods were applied, reaching either the targeted high-risk areas only or the whole institution (see Methods).

During the 16-week period after initiation of the promotion campaign, 1,416 (26\%) of 5,514 HCWs received influenza immunization, compared to 551 (10\%) of 5,432 HCWs during the same period the year 
TABLE 1

Reasons for Nonacceptance of Influenza Vaccine Among 757 Employees in Three High-Risk Areas (Geriatrics, Pediatrics, and Obstetrics) at the University Hospitals of Geneva

\begin{tabular}{|c|c|c|c|c|c|}
\hline \multirow{3}{*}{$\begin{array}{l}\text { Reason } \\
\text { Believe in own host defense }\end{array}$} & \multicolumn{4}{|c|}{ No. (\%) of Respondents } & \multirow{3}{*}{$\begin{array}{c}\mathbf{P} \\
\mathrm{NS}\end{array}$} \\
\hline & \multicolumn{2}{|c|}{ Total } & Nursing Personnel & \multirow{2}{*}{$\begin{array}{c}\text { Other Personnel } \\
129(31)\end{array}$} & \\
\hline & 258 & $(32)$ & 129 & & \\
\hline Not likely to get sick & 180 & (23) & $127 \quad(34)$ & $53(13)$ & .001 \\
\hline Vaccine doesn’t work & 154 & (19) & $86 \quad(23)$ & $68(16)$ & .02 \\
\hline Never had flu & 141 & (18) & 79 (21) & $62(15)$ & .02 \\
\hline To get flu doesn't bother & 125 & (16) & 56 (15) & $69(16)$ & NS \\
\hline Believe in homeopathic medicine & 108 & (14) & 59 (15) & $49(12)$ & NS \\
\hline Vaccination hours inconvenient & 108 & (14) & $39 \quad(10)$ & $69(16)$ & .01 \\
\hline Dislike immunization in general & 94 & (12) & 51 (13) & $43(10)$ & NS \\
\hline Other, not specified reasons & 88 & (11) & $44 \quad(12)$ & $44(11)$ & NS \\
\hline Too busy or forgot & 75 & (9) & $33 \quad(9)$ & $4210)$ & NS \\
\hline Fear of vaccine side effects & 72 & (9) & $42(11)$ & $30(7)$ & NS \\
\hline Dislike shots & 68 & $(8)$ & 47 (12) & $21(5)$ & .001 \\
\hline Got flu despite vaccination in the past & 49 & $(6)$ & $25 \quad(7)$ & $25(6)$ & NS \\
\hline Not informed about free immunization & 31 & $(4)$ & $10 \quad(3)$ & $21(5)$ & NS \\
\hline Reaction to vaccine in the past & 22 & $(3)$ & $10 \quad(3)$ & 12 (3) & NS \\
\hline Total responses & 1,573 & & 836 & 736 & \\
\hline Total employees & 797 & & 378 & 419 & \\
\hline
\end{tabular}

before $(P<.0001$, Table 2$)$. In the three targeted departments where all described interventions were applied, influenza immunization rates rose from $13 \%$ $\left(\mathrm{CI}_{95}, 11.4-15.6\right)$ in 1995 to 1996 to $37 \%\left(\mathrm{CI}_{95}, 34.5-\right.$ 40.3) in the following year $(P<.0001$, Table 2$)$. The highest increase was noted in the geriatric wards, where 142 (47\%) of 298 employees $\left(\mathrm{CI}_{95}, 41.9-53.5\right)$ were vaccinated in 1996 to 1997 compared to 31 (10\%) of 293 employees (CI95, 7.3-14.7) in 1995 to 1996 $(\mathrm{P}<.0001)$. In the other areas at HUG without special educational conferences and an available on-site employee-health nurse for immunization, the number of immunized healthcare personnel increased from 407 (9\%) of 4,356 employees $\left(\mathrm{CI}_{95}, 8.5-10.3\right)$ to 1,008 (23\%) of 4,422 ( $\mathrm{CI}_{95}, 21.6-24.1 ; P<.0001$, Table 2). Thus, vaccination coverage in the entire institution increased significantly, despite the fact that in these areas only a minor part of the intervention activities was applied. Importantly, however, the observed improvement in immunization rates was significantly higher $(P<.001)$ in the targeted areas compared to the other departments of the institution.

Analysis of immunization status by category of $\mathrm{HCW}$ is summarized in Table 3. As shown, compliance with immunization increased significantly among all categories of HCWs following the 1996 to
1997 promotion campaign (all $P<.001$, except for house staff, $P=.01$ ). The most compliant HCWs were physicians during both seasons (immunization rates $19 \%$ and 37\%, respectively). Nursing personnel remained more reluctant to accept influenza vaccine, despite a fourfold increase of their immunization rate in 1996 to 1997 compared to 1995 to 1996.

\section{DISCUSSION}

This study demonstrates that yearly recalls alone are not sufficient to promote influenza immunization among HCWs of a large healthcare institution, whereas understanding workers' concerns and designing specific intervention strategies based upon such concerns can prove effective. Furthermore, the results of this survey indicate that HCWs in high-risk areas of our institution have several misconceptions about the vaccine and influenza transmission, as previously reported. $4,5,8,9$

We observed significant differences between the concerns expressed by HCWs of our institution compared to those reported in North American studies (Table 4). In our study, the most frequently cited reason for nonacceptance of vaccine was HCWs' confidence in their own host-defense mechanisms against influenza (32\%). In contrast, the most fre- 


\section{TABLE 2}

IMPACT OF AN InfluenZa IMMUNIZATION CAMPAign ON COMPLIANCE OF HEALTHCARE Workers AT THE UNIVERSITY Hospitals of Geneva (HUG): Winter Season, 1995 to 1996 Compared to 1996 to 1997

\begin{tabular}{|c|c|c|c|c|c|c|}
\hline & \multicolumn{2}{|c|}{ Selected High-Risk Areas* } & \multicolumn{2}{|c|}{ Other Parts of HUG } & \multicolumn{2}{|c|}{ Overall } \\
\hline & 1995-1996 & 1996-1997 & 1995-1996 & 1996-1997 & 1995-1996 & 1996-1997 \\
\hline Total no. of employees & 1,076 & 1,092 & 4,356 & 4,422 & 5,432 & 5,514 \\
\hline No. of immunized employees & 144 & 408 & 407 & 1,008 & 551 & 1,416 \\
\hline Percentage & 13 & 37 & 9 & 23 & 10 & 26 \\
\hline $\mathrm{CI}_{95}^{\dagger}$ & $11.4-15.6$ & $34.5-40.3$ & $8.5-10.3$ & 21.6-24.1 & $9.4-11.0$ & $24.5-26.9$ \\
\hline
\end{tabular}

TABLE 3

Influenza Vaccine Compliance Among Different Categories of Healthcare Workers at the University Hospitals of Geneva: Winter Season, 1995 to 1996 Compared to 1996 to 1997

\begin{tabular}{|c|c|c|c|c|c|c|c|c|}
\hline \multirow{2}{*}{$\begin{array}{l}\text { Category of } \\
\text { Healthcare } \\
\text { Worker }\end{array}$} & \multicolumn{4}{|c|}{ 1995-1996 } & \multicolumn{4}{|c|}{ 1996-1997 } \\
\hline & \multirow{2}{*}{ 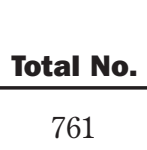 } & \multicolumn{2}{|c|}{$\begin{array}{c}\text { No. } \\
\text { Immunized (\%) } \\
\end{array}$} & \multirow{2}{*}{$\frac{\mathbf{C l}_{\mathbf{9 5}}}{16.4-22.1}$} & \multirow{2}{*}{$\begin{array}{c}\text { Total No. } \\
768\end{array}$} & \multicolumn{2}{|c|}{$\begin{array}{c}\text { No. } \\
\text { Immunized (\%) }\end{array}$} & \multirow{2}{*}{$\frac{\mathbf{C l}_{\mathbf{9 5}}{ }^{*}}{33.8-40.8}$} \\
\hline Physicians & & 145 & (19) & & & 286 & (37) & \\
\hline House staff & 106 & 13 & $(12)$ & $6.9-20.4$ & 100 & 27 & $(27)$ & $18.8-37.0$ \\
\hline Radiology technicians & 103 & 12 & (11) & $6.4-19.8$ & 106 & 34 & $(32)$ & $23.5-41.9$ \\
\hline Others $^{\dagger}$ & 1,810 & 218 & (11) & $10.6-13.6$ & 1,859 & 507 & (27) & 25.3-29.4 \\
\hline Nurses' aides & 563 & 45 & $(8)$ & 5.9-10.6 & 566 & 117 & (21) & $17.4-24.3$ \\
\hline Housekeeping staff & 161 & 12 & (7) & $4.1-12.9$ & 181 & 43 & (24) & 17.9-30.7 \\
\hline Midwives & 110 & 9 & (7) & $4.0-15.4$ & 115 & 28 & (24) & $17.0-33.4$ \\
\hline Physiotherapists & 201 & 15 & (7) & $4.4-12.2$ & 170 & 37 & $(21)$ & $16.0-28.9$ \\
\hline Registered nurses & 1,617 & 82 & $(5)$ & $4.0-6.3$ & 1,649 & 337 & $(20)$ & $18.5-22.5$ \\
\hline Total & 5,432 & 551 & (10) & $9.4-11.0$ & 5,514 & 1,416 & (26) & $24.5-26.9$ \\
\hline
\end{tabular}

quently cited reasons in North American studies were only mentioned by a minority of HCWs in our institution: avoidance of medications whenever possible $(33 \%-59 \%$ of surveyed HCWs in the United States $4,6,10$ ) and fear of adverse reactions (35\%$54 \% 5,6,8,11)$. Thus, intervention strategies that have been based upon HCWs' perceptions reported in other cultural settings would not have addressed the local concerns of HCWs at HUG specifically.

A common observation, however, is that time constraints and logistic barriers often contribute to a reduced vaccination coverage of busy HCWs. $9,11,12$ Thus, although our broad educational approach led to an increased vaccination coverage in the entire institution, the on-site availability of a vaccination nurse helped to increase immunization rates further in the targeted high-risk areas, a method also successfully used by others. 11,13

Unfortunately, the group of HCWs with the closest and most intimate contact with patients, the nursing personnel, was, and remained, the most reluctant to accept immunization. As reported by Weingarten and colleagues, ${ }^{4}$ this group of HCWs is likely to remain unconvinced unless their awareness of the danger of nosocomial influenza transmission to high-risk patients can be heightened.

In a recently published study from Glasgow, vaccination of $\mathrm{HCWs}$ in long-term-care hospitals was 
TABLE 4

Comparison of Major Reasons for Noncompliance Towards Influenza Immunization Among HealthCare Workers, as Reported in North American and European Studies

\begin{tabular}{|c|c|c|c|c|c|}
\hline Reference & Country & $\begin{array}{c}\text { Year of } \\
\text { Publication }\end{array}$ & $\begin{array}{l}\text { Population } \\
\text { Studied (N) }\end{array}$ & $\begin{array}{c}\text { First Two } \\
\text { Rejecting Criteria* }\end{array}$ & $\%$ \\
\hline \multirow[t]{2}{*}{8} & United States & 1985 & 206 & Fear of adverse reactions & 39 \\
\hline & & & & Belief that the vaccine is not protective & 24 \\
\hline \multirow[t]{2}{*}{4} & United States & 1989 & 174 & Avoid medication whenever possible & 59 \\
\hline & & & & Vaccine administration inconvenient & 31 \\
\hline \multirow[t]{2}{*}{10} & United States & 1991 & 379 & Avoid medication whenever possible & 47 \\
\hline & & & & Concern about getting influenza from the vaccine & 45 \\
\hline \multirow[t]{2}{*}{11} & United States & 1992 & 263 & Inconvenience & 59 \\
\hline & & & & Fear of secondary febrile illness & 54 \\
\hline \multirow[t]{2}{*}{5} & United States & 1993 & 724 & Heard it had bad side effects & 37 \\
\hline & & & & Do not like shots & 27 \\
\hline \multirow[t]{2}{*}{9} & Canada & 1994 & 353 & Never got offered the vaccine & 35 \\
\hline & & & & Influenza is not a serious illness & 21 \\
\hline \multirow[t]{2}{*}{12} & United States & 1994 & 38 (only residents) & Never had time & 42 \\
\hline & & & & Never remembered to receive vaccine & 24 \\
\hline \multirow[t]{2}{*}{15} & Italy & 1994 & 752 & Assumption of not contracting the disease & 58 \\
\hline & & & & Risk of postvaccination reactions & 11 \\
\hline \multirow[t]{2}{*}{6} & United States & 1995 & 922 & Fear of side effects & 35 \\
\hline & & & & Avoidance of medications & 33 \\
\hline \multirow[t]{2}{*}{16} & United States & 1997 & 152 & Concern about side effects & 36 \\
\hline & & & & Not in target group & 15 \\
\hline \multirow{2}{*}{$\begin{array}{l}\text { Present } \\
\text { study }\end{array}$} & Switzerland & 1997 & 797 & Believe in own host defense & 32 \\
\hline & & & & Not likely to get sick & 23 \\
\hline
\end{tabular}

* In all surveys, respondents gave more than one reason.

associated with a reduced rate of patient mortality and influenza-like illness. ${ }^{3}$ Although our study was not designed to assess the efficacy of influenza immunization of HCWs, we can postulate on the basis of the above-cited study ${ }^{3}$ that the threefold increase of vaccination coverage of $\mathrm{HCWs}$ in high-risk wards contributed to the protection of a substantial number of patients who were not immunized at the time of hospital admission. Nevertheless, further efforts (eg, personal telephone contacts with reluctant employees) are necessary to increase HCWs' immunization rates and to improve the efficacy of our program.

There are several potential limitations in the interpretation of our results. First, we did not test the generalizability of the responses in our survey. However, a high response rate (73\%) compared to other studies 5,8 suggests that no major bias occurred by excluding the nonresponders from the analysis, as observed by Pachucki and colleagues who showed in their survey that responses of nonresponders were similar to responders. ${ }^{8}$ Second, vaccination of HCWs may add benefits by reducing incidence of clinical influenza and thus decreasing work time lost due to illness. ${ }^{14}$ Although absenteeism among HCWs could have been measured and compared between 1995 to 1996 and 1996 to 1997, assessment of the part of work time lost due to influenza disease would have been extremely labor-intensive and beyond the scope or our study. Last, we could not assess the influence of a nationwide media campaign promoting influenza immunization, which was more extensive than in previous years. This factor might emerge more clearly during the next season, during which we plan to continue and extend our successful initial efforts, including educational conferences and the on-site availability of a vaccination nurse in most areas of our institution.

\section{REFERENCES}

1. Hoffman PC, Dixon RE. Control of influenza in the hospital. Ann Intern Med 1977;87:725-728.

2. Centers for Disease Control and Prevention. Prevention and control of influenza: recommendations from the immunization practices advisory committee (ACIP). MMWR 1992;41:1-17.

3. Potter J, Stott DJ, Roberts MA, Elder AG, O’Donell B, Knight $\mathrm{PV}$, et al. Influenza vaccination of health care workers in longterm-care hospitals reduces the mortality of elderly patients. $J$ 
Infect Dis 1997;175:1-6.

4. Weingarten S, Riedinger M, Bolton LB, Miles P, Ault M. Barriers to influenza vaccine acceptance. A survey of physicians and nurses. Am J Infect Control 1989;17:202-207.

5. Watanakunakorn C, Ellis G, Gemmel D. Attitude of healthcare personnel regarding influenza immunization. Infect Control Hosp Epidemiol 1993;14:17-20.

6. Heimberger T, Chang HG, Shaikh M, Crotty L, Morse D, Birkhead G. Knowledge and attitudes of healthcare workers about influenza: why are they not getting vaccinated? Infect Control Hosp Epidemiol 1995;16:412-415.

7. Fleiss JL. An introduction to applied probability. In: Fleiss JL, ed. Statistical Methods for Rates and Proportions. 2nd ed. New York, NY: John Wiley \& Sons; 1981:1-19.

8. Pachucki CT, Lentino JR, Jackson GG. Attitudes and behavior of health care personnel regarding the use and efficacy of influenza vaccine. J Infect Dis 1985;151:1170-1171.

9. Yassi A, Murdzak C, Cheang M, Tran N, Aoki FY. Influenza immunization: knowledge, attitude and behaviour of health care workers. Canadian Journal of Infection Control 1994;9:103108.

10. Christian MA. Influenza and hepatitis B vaccine acceptance: a survey of health care workers. Am J Infect Control 1991;19:177184.

11. Ohrt CK, McKinney WP. Achieving compliance with influenza immunization of medical house staff and students. A randomized controlled trial. JAMA 1992;267:1377-1380.

12. Nafziger DA, Herwaldt LA. Attitudes of internal medicine residents regarding influenza vaccination. Infect Control Hosp Epidemiol 1994;15:32-35.

13. Adal KA, Flowers RH, Anglim AM, Hayden FG, Titus MG, Coyner BJ, et al. Prevention of nosocomial influenza. Infect Control Hosp Epidemiol 1996;17:641-648.

14. Weingarten S, Staniloff H, Ault M, Miles P, Bamberger M, Meyer RD. Do hospital employees benefit from the influenza vaccine? A placebo-controlled clinical trial. J Gen Intern Med 1988;3:32-37. 